\title{
Deceptive Foreign Credential Evaluation Services
}

\author{
GEORGE D. GOLLIN
}

George D. Gollin is professor of physics, University of Illinois at UrbanaChampaign. E-mail: g-gollin@illinois.edu.

A year after entering practice in Africa, the young African physician appeared to be seeking employment in Greece. He asked a credential evaluation service to vouch for the legitimacy of his medical degree, sending a report of its conclusions to his new home country (Greece). The service promised "fair \& honest evaluations," and claimed it was "fighting degree frauds through professional techniques and verifications." It determined "that applicant's studies have the equivalency of a Doctor of Medicine ... from a regionally accredited Institution of Higher Education of the United States of America."

The report failed to mention that the credential evaluation firm's owner was himself a perpetrator of degree frauds, having been fined $€ 15,000$ for running a diploma mill in Europe. The medical degree frauds came from a Pakistani mill, which had once tried to sell me a doctoral degree in thoracic surgery. However, I am a physicist, not a physician.

Another credential evaluator was paid by the owners of a North American diploma mill for pretending that they ran a recognized African school, rather than a criminal enterprise based in the United States. A third employed an 
unsavory fellow who was the "Vice President" and "Dean of Studies" of a pair of diploma mills.

There are many legitimate credential evaluation services in the higher education landscape, but also plenty of snakes in the weeds.

\section{Foreign Credential Evaluation Services}

The rapid changes in international higher education complicate the decision process, regarding transfer of credits when students cross national boundaries. Since it is costly to maintain in-house expertise in the evaluation of foreign programs, it is natural for universities and employers to seek the analyses of outside experts-such as the International Education Services division of the American Association of Collegiate Registrars and Admissions Officers (AACRAO), or the National Association of Credential Evaluation Services (NACES). Members of the ENIC-NARIC Networks (ENIC: European Network of Information Centers in the European Region; NARIC: National Academic Recognition Information Centers in the European Union) also provide reliable credential evaluation services.

Unfortunately, there is no regulatory oversight in the United States of the hundreds of foreign credential evaluation services. Even an evaluator's membership in a professional association is sometimes uninformative: in 2009, a credential evaluator who had worked with the notorious "St. Regis University" invited legitimate evaluators to join an impressively named recognition mill intended to help "the smaller independent agencies to unite and receive greater acceptance." Most of the entities already listed as members were cooperating with known diploma mills. And NAFSA, the well-respected Association of 
International Educators, cautions that NAFSA membership does "not imply that NAFSA has reviewed or endorsed their programs or activities, or that NAFSA membership confers any endorsement." NACES members are held to standards, but only 21 evaluators are currently listed by the organization as members.

How is a corporate personnel office to tell the difference between the legitimate Foreign Credentials Service of America and the bogus agency, which plagiarized extensively from FCSA and then closed abruptly when its American owners were charged with mail and wire fraud a year later?

\section{A Paucity of Info Facilitates Deception}

It can be surprisingly difficult to find good information about a school's degree granting authority. Sometimes there are subtleties: in the United States, the Council for Higher Education Accreditation (CHEA) maintains an accurate database of accredited programs and universities, but degree granting authority in the US issues from the states, rather than the federal government. Legitimate schools that do not seek accreditation are absent from the CHEA database.

Sometimes information about a country's universities is incomplete, unavailable, or unreliable. After the end of Liberia's civil war, that nation's only published list of recognized universities was on the Web site of Liberia's embassy in the United States. But the embassy's chief and deputy chief of mission were taking bribes from the owners of an American mill and had granted them control of the Web site. The list of "recognized" schools included their diploma mills, until a new ambassador ejected the scoundrels. The UNESCO (United Nations Educational, Scientific, and Cultural Organization) Portal to Recognized Higher Education Institutions is incomplete-only three 
African countries are listed-while the more extensive Electronic Database for Global Education, managed by AACRAO, requires a paid subscription.

In my experience, most deceptive evaluations misrepresent a degree provider's authority to issue degrees. The absence of a universally accessible, exhaustive database of recognized schools allows corrupt evaluators to sell their services to the customers of diploma mills.

Sometimes dishonest credential evaluators will offer gross misrepresentations in their comparisons of the legitimate academic programs of different countries. An example was an analysis of one country's three-year degrees, which suggested based on judgments by others that those degrees did not correspond to US bachelor's degrees arose racial prejudice, rather than a thoughtful evaluation of the academic programs in question. The authors-both of whom have known associations to degree mills-came to conclusions that would undoubtedly attract prospective customers seeking exaggerated evaluations of their credentials.

\section{DISSEMINATION OF INFORMATION IN A LITIGIOUS WORLD}

Documenting the identities and practices of higher education fraudsters, publicly posted and indexed by Google, accurate information can be devastating to the diploma mill industry. The monthly income of St. Regis declined steadily from a high of $\$ 250,000$ in December 2004, to just a few thousand dollars in August 2005, thanks to a mix of hostile news coverage and unflattering analyses published to the Internet. Exposure of the deceptive practices of dishonest credential evaluators could also be an effective tool for their suppression. 
One possible repository for documentation would be a government agency, which would receive reliable information from higher education professionals (including favorable evaluations of diploma mill degrees), then publish it. But the revelation of such information carries risks to the whistleblowers, ranging from lawsuits to threats of violent retribution. For several years, Oregon posted a useful (but incomplete) list of diploma mills. The state was regularly threatened with legal action by the operators and customers of degree mills and eventually removed the material from the worldwide Web.

Given the international nature of the dark sector, which markets false academic credentials, it would be sensible for UNESCO to assume responsibility for an information archive. But that would require a commitment of will and resources that have not been forthcoming. 